\title{
OS CAMINHOS CRUZADOS ENTRE ÉTICA E METAFÍSICA NO CONCEITO DE RESPONSABILIDADE
}

The Cross Paths between Ethic and Metaphysics in the Responsibility Concept

\section{Luciano Gomes Brazil}

Mestre em Filosofia pelo IFCS-UFRJ

RESUMO: O presente artigo, em verdade um pré-projeto de doutorado, procura entender o status da Responsabilidade no âmbito ético metafísico da obra de Hans Jonas, em específico $O$ Princípio Responsabilidade. O elementar dessa pesquisa é a pergunta de como se dá essa relação entre aquilo que é ético e aquilo que é metafísico, pois ao esmiuçar o lugar dos fins no ser, estabelecendo os fins imanentes, e em seguida ao fazer a passagem da doutrina dos fins para a doutrina do valor, estabelecendo aquilo que tem valor imanente; ao realocar o homem no todo da vida a partir de uma nova interpretação sobre o organismo, a Responsabilidade redimensiona o homem em sua relação com o mundo e consigo mesmo. O pré-projeto pergunta que metafísica é essa que gera uma ética da responsabilidade; como se dá essa relação entre ética e metafísica e como ela se sustenta.

PALAVRAS-CHAVE: Deontologia; Responsabilidade; Hans Jonas; Técnica; Ética.

ABSTRACT: The present article, in fact a pre-project of $\mathrm{PhD}$, looks to know the status of Responsibility in the scope metaphysical ethic of the work of Hans Jonas, specifically The Principle Responsibility. The elementary of that search is the the question of how happens that relation between that is ethical and that is metaphysical, for to scrutinize the place of the ends in the Being, establishing Immanent ends, and after that, when making the passage of the ism of ends to the ism of value, establishing that what has immanent value; when reallocate the Man in the all of life starting from a new interpretation about the organism, the Responsibility resize the man in his relation with the world and himself. The pre project ask for what metaphysic is this that generates an ethics of Responsibility; how it happens that relation between ethic and metaphysic and how it sustain itself.

KEYWORDS: Deontology; Responsability; Hans Jonas; Technic; Ethic. 
O Princípio Responsabilidade, obra monumental de Hans Jonas e publicada em 1979, propõe uma renovação da deontologia a partir de pressupostos inéditos para a história da ética. Tal ineditismo, porém, não é conduzido por Jonas sem um explícito engajamento na história dos problemas da disciplina ética e àquilo que lhe é exigido. O texto a seguir procura se inserir nesta exigência a partir de um problema ou dificuldade que surge já mesmo em seu título, e que, dentro dos recursos exegéticos que dispomos aqui tentaremos, ao invés de responder, colocar as perguntas corretas para um projeto que se abre. Ou seja, não é compromisso deste artigo responder ou mesmo dar conta de uma possível resposta a possíveis problemas, mas sim colocar as devidas questões e formulá-las de acordo com o que um projeto de doutoramento nos cobra.

Para que o caminho a ser feito seja o melhor possível, deixemos bem claro o que precisamos primeiro estabelecer. Há três pontos fundamentais que gostaria de seguir:

O primeiro diz respeito, e deixemos que isso soe já de antemão, antes mesmo de nos engajarmos à leitura do texto, diz respeito ao fato de que Jonas se propõe uma renovação da deontologia, isto é, à ética do dever; o segundo ponto é que Jonas funda essa deontologia a partir da metafísica, e este é o ponto que considero central nos problemas que pretendo abrir neste projeto: o de que Jonas trabalha com algo como um imbricamento ético metafísico para a sua deontologia; o terceiro ponto é que essa ética deontológica imbricada em uma metafísica surge em meio ao universo tecnológico contemporâneo e àquilo que ele exige de nós enquanto seres humanos.

Cada uma das afirmações acima carece de elucidação, e é o que faremos a seguir. Jonas nomeia o livro em questão de O Princípio Responsabilidade, e indica no subtítulo que se trata de um “ensaio de uma ética para a civilização tecnológica”. O ponto de partida é, então, a civilização tecnológica. O que é que essa dita civilização tecnológica exige e qual a sua grande novidade em face ao passado? Jonas nos fala de uma "natureza modificada do agir humano". O que isso quer dizer?

Ele nota uma alteração da ação humana, de sua própria natureza, agora imbricada com um poder tecnológico de longo alcance. Para dizermos em poucas palavras, a natureza modificada mencionada pelo autor alemão é o agir do homem no mundo contemporâneo da técnica. É a técnica, em última instância, que determina essa natureza modificada do agir. Através da realização da técnica, o homem de hoje se vê diante de desafios inéditos, pois o poder da ação través dela apresenta ao agente novos objetos, que em sua totalidade engloba a "biosfera inteira do planeta".

\footnotetext{
${ }^{1}$ JONAS, Hans. O Princípio Responsabilidade: ensaio de uma ética para a civilização tecnológica. Tradução de Marijane Lisboa e Luiz Barros Montez. Rio de Janeiro: Contraponto: ed. PUC-RJ, 2006, p.26
} 
Em sua relação com a natureza (mundo natural), por outro lado, a situação se inverte. Partindo de um paradigma ético, o "exemplo da antiguidade", exemplar no famoso canto do coro trágico de Antígona, peça teatral de Sófocles, Jonas demonstra que nessa antiguidade longínqua o homem ao mesmo tempo em que se pronunciava de um modo bastante altivo quanto ao poder de sua ação, permanecia ainda submetido a um poder infinito do próprio mundo natural: "O que ali não está dito, mas que estava implícito para aquela época, é a consciência de que, a despeito de toda grandeza ilimitada de sua engenhosidade, o homem, confrontado com os elementos, continua pequeno"2.

Criatura admirável, mais admirável dentre todas, o homem não dispunha de condições de se alçar sobre esse dito mundo natural, e isso sequer era colocado sob suspeita. Os recursos não eram esgotáveis e os ciclos não eram alterados ${ }^{3}$.

Como dissemos, essa relação se inverte no mundo contemporâneo. Os caminhos que conduzem a esta alteração não podem ser alienados de um estudo que se pergunta por uma ética contemporânea. Os questionamentos acerca da técnica envolvem o lugar que o homem coloca a si próprio no interior do mundo natural; o lugar e o status que o mundo natural ocupa na sua compreensão acerca do agir, do saber e do poder. Em suma, há toda uma nova dimensão que se descortina a partir da constatação disso que Jonas chama de "natureza modificada do agir humano":

já que a ética tem a ver com o agir, a consequência lógica disso é que a natureza modificada do agir humano também impõe uma modificação da ética. E isso não somente no sentido de que os novos objetos do agir ampliaram materialmente o domínio dos casos aos quais se devem aplicar as regras de conduta em vigor, mas em um sentido muito mais radical, pois a natureza qualitativamente nova de muitas das nossas ações descortinou uma dimensão inteiramente nova do significado ético, não prevista nas perspectivas e nos cânones da ética tradicional. ${ }^{4}$

De algum modo a ação humana atingiu um poder e uma capacidade de gerar efeitos que o mundo natural finalmente se mostrou frágil ante a tal ação. $\mathrm{O}$ instrumento para esses efeitos é o que chamamos tradicionalmente de técnica: o universo tecnológico é o reino da técnica que submete a natureza e os homens a seu poder. De algum modo a técnica como instrumento dá lugar a uma tecnologia autômata e é ela quem determina o seu próprio progresso.

O nosso autor nos fala, no segundo capítulo, de uma "dinâmica cumulativa dos desenvolvimentos éticos" ${ }^{5}$. Essa constatação se soma a outra, que remete ao perigo exposto da evolução tecnológica que é inversamente proporcional à evolução natural: a de que a cada passo

\footnotetext{
2 Id.Ib., p. 29

${ }^{3}$ Id.Ib.,p.32

${ }^{4}$ Id.Ib., p.32

5 Id.Ib., p. 78
} 
dado pelo progresso técnico, mais abismal se tornam suas relações. Além de serem irreversíveis os avanços, eles são cumulativos, isto é, eles cobram mais e mais rigor tecnológico para o passo seguinte. Talvez seja nessa medida que Jonas constate que o grande perigo do mundo contemporâneo não esteja do lado do seu fracasso, mas justamente de seu sucesso, e por isso exige de nós uma certa humildade, uma humildade que reconheça o poder supremo de nossas ações. É que se na antiguidade o poder de nossas ações cobrava dos pensadores uma ética imediata, sem refletir sobre um longo alcance da ação - simplesmente porque esses efeitos longos inexistiam -, o mundo contemporâneo da tecnologia nos exige uma nova ética, e não basta a ela apenas hiperdimensionar os efeitos ativos da humanidade e de sua tecnologia, mas de se valer de uma profunda pergunta metafísica e que gere consequentemente um sentimento de responsabilidade desse homem contemporâneo.

Jonas ao apresentar essa natureza modificada do agir e situar um poder de intervenção que atue numa esfera global, não está apenas hiperdimensionando o objeto de reflexão ética, mas atravessando campos de saberes supostamente distintos, ou seja, saindo da ética, que tradicionalmente coloca a pergunta do agir (o que fazer, como fazer) para o âmbito da metafísica (qual o fundamento para determinada ação). É isso o que o próprio Jonas diz após apresentar a natureza modificada do agir humano: “estender a reflexão sobre as alterações mencionadas e avançar além da doutrina do agir, ou seja, da ética, até a doutrina do existir ou seja, da metafísica, na qual afinal toda ética deve estar fundada",

Portanto, para elucidarmos aquele terceiro ponto, que foi de onde partimos, o autor de The Phenomenon of Life constata um poder de causar efeitos muito superior a tudo o que já fora pensado por todas as éticas e conjunto de valores tradicionais. Mas a incrível capacidade hiperdimensionada gera não somente que se tenha também uma atenção hiperdimensionada de seus efeitos. É preciso reconhecer que o poder de atuação do mundo tecnológico atual faz cair sobre os nossos braços a decisão pela consequência, uma decisão que envolve uma amplitude de decisão não mais ao que as éticas tradicionais elegeram como seus objetos: o próprio homem, não apenas somente o homem, mas o homem de agora, da relação imediata, ao "círculo imediato da ação"”. É justamente o Bem que agora assume outra significação e que precisa ser indagado tendo em vista que o objeto da ação humana não mais se delimita ao imediato do efeito individual. O filósofo alemão entende que o caminho para se elucidar esse dilema ético é chegar aos questionamentos da doutrina metafísica, que é o que se pergunta e decide acerca da existência das coisas em geral. Assim, passamos do terceiro ponto ao segundo. Note-se que ainda não mencionamos qualquer hipótese ao dever.

\footnotetext{
${ }^{6}$ Id.Ib., p.42
}

${ }^{7}$ Id.Ib., p. 36 
Mas há algo que precisa ser esclarecido e que de certa forma antepõe o que virá a seguir. Antes mesmo de fundamentar a ética, Jonas dedica todo um capítulo a "Questões de Princípio e Método", e é neste capítulo que se estabelece a "heurística do Temor". A reflexão sobre o Bem elege para si próprio uma delimitação. Cito Jonas: “o reconhecimento do malum é infinitamente mais fácil do que o do bonum, é mais imediato, mais urgente, bem menos exposto a diferenças de opinião; acima de tudo, ele não é procurado"”.

O contexto de reflexão da citação acima é o futuro como problema. O núcleo de onde brota toda a questão da teoria da Responsabilidade é a possibilidade, não mais virtual, de aniquilamento de espécies inteiras, é o sentimento apocalíptico de aniquilação. A heurística do temor é:

tomar o temor como procedimento heurístico. Mas que conhecimento está implicado aí? 'Trata-se do conhecimento da 'futurologia', que Jonas define como a 'projeção cientificamente informada do que nossos atos presentes podem causalmente conduzir ${ }^{10}$

É uma passagem crucial nessa teoria ética, pois a fundamentação dessa metafísica estabelecida por Jonas de algum modo elege seus objetos a partir de um elo afetivo, porém não pelo caminho do desejo, mas do temor, o que para o autor é motivo de um importante questionamento. É um passo importante na teoria da Responsabilidade, onde Jonas precisa refutar, sobretudo, Kant. Cabe lembrar ainda que uma heurística do Temor cobra dessa ética um comprometimento teórico, um conhecimento, que, no entanto, não se limita ao científico. Cito o autor:

Dissemos que a verdade nele [do dever] buscada seria uma questão de conhecimento científico: pois, assim como os empreendimentos (cujas consequências posteriores devemos conhecer pela extrapolação) só se viabilizam por meio da ciência, da mesma forma essa extrapolação requer, no mínimo, o mesmo grau de ciência utilizado nos próprios empreendimentos. Entretanto, ela exige de fato um grau maior. Pois o que basta para um prognóstico de curto prazo, intrínseco a todas as obras da civilização técnica, não pode bastar para o prognóstico de longo prazo almejado na extrapolação requerida pela ética. A certeza de que desfruta a primeira, e sem a qual a empresa tecnológica inteira não poderia funcionar, encontra-se para sempre recusada à outra ${ }^{11}$.

A relação e a tensão entre a techné, conhecimento (epistemê) e a ética é, desde os antigos, um motivo de discussão. Considero esse um capítulo importante de discussão e problematização para

\footnotetext{
¿ Segundo as indicações de Wendel Evangelista, a palavra adequada para se utilizar é "Temor", e não "Medo".

${ }^{9}$ Op.cit. 2006. P. 71

${ }^{10}$ EVANGELISTA, Wendel. A Fundamentação Metafísica do Princípio Responsabilidade em Hans Jonas. 2008. $140 \mathrm{f}$. Dissertação (Mestrado em Filosofia) - Faculdade Jesuíta de Filosofia e Teologia, Belo Horizonte. <Disponível em http://www.faculdadejesuita.edu.br/documentos/180915-K9SrJvvkVEd.pdf acessado em 05 julho 2016>. P.103 11 Op.Cit. 2006, p.73
} 
os questionamentos necessários acerca do lugar metafísico dessa ética da responsabilidade. Sabemos que para Sócrates, o conhecimento do Bem envolvia necessariamente a realização desse Bem. Mas que tipo de conhecimento era esse? Por que necessariamente o conhecimento do Bem envolve um comprometimento ético do agente? Bem diferente é o entendimento acerca desse tema no interior da filosofia cristã, para quem conhecer o bem não necessariamente remete à sua realização. Para Agostinho, o livre arbítrio humano, origem do mal, impõe a distância entre o conhecer o Bem e o fazer o Bem. O quanto essa discussão inteira é importante e contribui para o debate acima? No mundo tecnológico, a possibilidade de aniquilação, individual ou coletiva, convive com as atividades mais habituais. O quanto a concepção de Bem do mundo antigo, e de Mal, da filosofia cristã, pode nos favorecer acerca da instigante questão da responsabilidade e com o futuro? O quanto o conhecimento científico pode nos favorecer quanto à promoção do Bem? Onde reside o limite de sua atuação?

Jonas nos diz que a ética deve buscar sua fundamentação lá na metafísica, que é a "doutrina do existir". Dissemos acima que há algo como um imbricamento entre ética e metafísica, que em algum lugar elas são, podemos afirmar, inerentes, ou ao menos se confundem. Conhecer as suas fronteiras é o objetivo deste projeto, é em virtude dele que se dá o engajamento às questões jonasianas.

Hans Jonas propõe uma ética deontológica. Ele resgata do constructo moral kantiano a noção de dever. E é justamente em seus fundamentos, ou seja, em sua metafísica, onde ele mais irá discordar de seu conterrâneo alemão. A relação de Kant com a metafísica nós já conhecemos, ainda que a conclusão acerca desta não possa nunca ser feita isenta de discussões: Kant estabelecera a impossibilidade de conhecimento dos objetos metafísicos: Deus, alma e mundo como um todo, algo que de algum modo irá se relacionar com a fundamentação de uma metafísica dos costumes (pois se assenta sobre a clássica distinção kantiana entre filosofia pura e empírica $^{12}$ ). Que a metafísica kantiana a partir da perda do objeto metafísico conhecido através de meros conceitos tenha se compensado numa ética fundamentada metafisicamente não é nosso principal interesse aqui (apesar de acenarmos para este tema como questão secundária), mas que essa ética kantiana tenha se fundamentado a partir da homologia entre vontade e razão é demasiado importante para ressaltar a quebra jonasiana de paradigma e, portanto, se relaciona diretamente com a nossa questão principal. Jonas: “o que importa são as coisas, e não o estado de

\footnotetext{
${ }^{12}$ KANT, Immanuel. Fundamentação da Metafísica dos Costumes. Tradução, introdução e notas de Guido Antônio de Almeida. São Paulo: Discurso Editorial: Barcarolla, 2009 (Coleções Philosophia), Prefácio
} 
minha vontade" ${ }^{\prime 13}$. O deslocamento jonasiano parece ter pressupostos fenomenológicos, e esta base metodológica não é novidade na crítica ao formalismo kantiano ${ }^{14}$.

Jonas, porém, foi além. É desde a sua base ontológica que a ética da Responsabilidade mostra ao que veio. Ao derivar valor imanente da finalidade imanente, Jonas está em verdade estabelecendo que a possibilidade de um valor, que coincide com a capacidade de ter fins, já é em si um valor ${ }^{15}$. Assim, para cada ente, o exercício de sua finalidade imanente lhe dá a dignidade própria, ou seja, a não indiferença em função de si mesmo já é um valor imensurável ante o não ser. Já aqui Jonas fala de maneira bastante distinta da fenomenologia. O que esta posição dos fins no Ser carrega de novidade ante as teorias tradicionais? Primeiramente, ela desloca a centralidade da subjetividade e da racionalidade humana, tradicionalmente (ao menos, e de maneira gradualmente mais incisiva na modernidade) detentora do telos, para o todo da vida.

Até aqui não temos ainda uma ética, apenas uma ontologia ou uma ontobiologia que modifica o locus do homem no todo da natureza. Mas não é justamente esta a nossa questão? $\mathrm{O}$ quanto a ontologia ela própria já nos apresenta tudo aquilo que a ética tratará de resolver? É justamente em face do lugar no todo da vida que se ergue a construção ética. Que essa construção tenha de ser em face de um dever ser, é em torno disto que gira toda a problemática: como elucidar essa deontologia? Que pressupostos devem estar contidos na noção de imanência dos fins para que eles possam realizar a contundência de um dever ser? A imanência dos fins e a teoria da responsabilidade dão conta de pensar os problemas contemporâneos? A exigência ética de nosso tempo carece de algo como uma fundamentação metafísica? Que metafísica é essa de que carece a ética? Sabemos que a ética que se segue é inteiramente baseada no locus que descentraliza o homem do antropocentrismo racionalista. Se há uma premissa básica de que toda ética pressupõe uma antropologia filosófica, ela nunca foi tão verdadeira. Sganzerla:

É preciso considerar, portanto, que o autor propõe uma "biologização do ser moral" e não uma "biologização da moral" ou mesmo uma "moralização da natureza". A diferença estaria justamente no fato de que Jonas não retira simplesmente da natureza a moralidade e nem sequer usa a natureza como regra para a moralidade, mas reafirma a pertença do homem (ser moral) ao reino da natureza (numa espécie de ontobiologia) ${ }^{16}$.

\footnotetext{
13 Op.cit. 2006, p.163

${ }^{14} \mathrm{O}$ próprio Jonas nos remete à leitura de Max Scheler. Cf. SCHELER, M. Der Formalismus in der Ethik und die Materiale Wertethik: Neuer verluch der Grundlegung eines ethischen Personalismus. [Freiburg?]: Max Niemeyer verlag, $1916<$ Disponível em

https://archive.org/stream/DerFormalismusInDerEthikUndDieMaterialeWertethik/Max Scheler Der Formalism us in der Ethik\#page/n1/mode/2up acessado em 30 agosto 2016>

15 Op.Cit. 2006, Capítulo IV O Ber, O Dever, O Ser: Teoria da Responsabilidade.

16 SGANZERLA, Anor. Biologização do ser moral em Hans Jonas. Revista de Filosofia Aurora. Curitiba, V.25, n.36, p.155-178, jan./jun.2013 <Disponível em file:///C:/Users/181/Downloads/rf-7769.pdf acessado em 06 julho 2016>, p.160-161
} 
Manter distante a moral e a vida a não confundi-los permite que estejamos seguros de que Jonas escapou de algumas falácias, entre elas a falácia naturalista, elucidada por Hume, que estabelecia uma impossibilidade de se passar da ontologia para a axiologia, devido à natureza diferentes do objeto ontológico e moral, respectivamente. A falácia naturalista é caso para discussão, e não podemos nos esquivar dela no itinerário de nossa pesquisa. Prossigamos:

Note-se que estamos interessados no conceito de natureza em função da doutrina da finalidade, e não ao contrário; não nos interessamos pelo conceito de finalidade em função da doutrina da natureza. Queremos - em última análise, em função da ética - ampliar o lugar ontológico da finalidade como um todo $(. . .)^{17}$

A nossa questão aqui é buscar compreender em que momento começa a metafísica e em que momento começa a ética. Textualmente ela é visível, porém, justamente em face de sua exigência, a de um imperativo “ontológico", não sabemos de que modo estabelecer uma fronteira entre o ético e o metafísico, se é que assim podemos proceder. Vimos acima que a biologização do ser moral não pode se confundir com a biologização da moral - algo que salva Jonas de um estoicismo, perguntamo-nos - pois o encargo moral não cabe à natureza, nem uma moralização da natureza, pois a moral é peculiar ao homem. Mas isso não quer dizer que a ética se aparte da metafísica ou vice-versa. Aliás, podemos dizer com segurança o contrário, de que para Jonas o que falta à ética é justamente metafísica, e ao estabelecer a teoria da Responsabilidade, ele o faz em favor da inerência entre o que é ético e o que é metafísico: "Através da imanência dos fins no Ser, a batalha decisiva pela teoria da ética já havia sido ganha"18.

Princípio Responsabilidade quer dizer justamente sobre a inerência que há entre o ético e o metafísico. Devemos perguntar afinal: que metafísica é essa que gera a ética da responsabilidade? O procedimento jonasiano não adere à responsabilidade como matéria prima para um princípio ("da” Responsabilidade) ${ }^{19}$, assim como à Vida. São dois princípios inerentes, a responsabilidade é o princípio; a vida é o princípio $^{20}$ !!

\footnotetext{
17 Op.Cit.2006, p.136

18 Op.Cit. 2006, p.146

${ }^{19}$ É o que eu explico em meu único artigo publicado sobre o autor: "O nome deste ensaio e, portanto, o nome dessa ética para esta tal civilização tecnológica clama por uma responsabilidade e a clama de uma maneira que precisaremos refletir. Por que Princípio Responsabilidade e não meramente e usualmente Princípio da Responsabilidade? Entre o uso e o não uso da preposição é possível notar uma concepção do tema proposto. Vejamos: Se disséssemos da Responsabilidade a preposição conferiria ao termo antecedente a preponderância que rege a relação e a conexão deste com o outro termo. De tal modo que se disséssemos que o ensaio propõe um Princípio da Responsabilidade estaríamos supondo que há aí uma ética que busca refletir sobre a responsabilidade e retirar daí um princípio possível, talvez aplicável. Aplicável ao que? À Civilização tecnológica? A responsabilidade seria, portanto, uma matéria prima cuja ética vem a dar validade, ao formata-la na qualidade de um princípio? (...) Isto não se sustentaria: Princípio Responsabilidade quer dizer, sobretudo, que a Responsabilidade é o Princípio.” (BRAZIL, 2016, p.125-126)

${ }^{20}$ Cabe lembrar que a obra traduzida para o português como "Princípio Vida" possui no original em inglês um título diverso, mais facilmente traduzível não como "Princípio", mas sim "Fenômeno": The Phenomenon of Life.
} 
Entre o Princípio Vida e o Princípio Responsabilidade o que testemunhamos é que, uma vez descentralizado o homem em relação à natureza através de uma reinterpretação da vida e da subjetividade, temos por outro lado a localização da Responsabilidade no homem como aquele que detém o dom de agir em função do todo, não apenas no imediato do tempo e do espaço. Se, através da tradição, nós podíamos afirmar, sem muito embaraço, dois territórios distintos e com fronteiras bem definidas, de um lado o terreno da ontologia, cuja meta de seu saber era desvelar a necessidade, e de outro lado o terreno da ética, cuja preocupação principal se ocupava em estabelecer a liberdade, agora, sem os muros que dividiam o terreno temos que dar conta da liberdade e da necessidade sem sermos seduzidos pelo dualismo oposicionista. Em verdade, é justamente a liberdade o que redimensiona a ética da Responsabilidade no todo da vida, pois cada vivente já manifesta liberdade ${ }^{21}$. O entendimento do lugar da ética e do lugar da metafisica diante deste todo reconfigurado é o nosso propósito.

A nossa questão aqui é entender a) como se dá a passagem que vai da metafísica para a ética e b) como se sustenta essa relação. As indicações para ambos os propósitos aparecem ao longo de todo O Princípio Responsabilidade.

Pelo fato de o objeto ético ser de uma natureza inteiramente distinta do objeto da ética tradicional, é de se esperar que a metafísica de onde ela parte, ou ao menos o modo como essa relação entre ética e metafísica se dá, seja de um teor inteiramente distinto também. É nesse ponto que a pesquisa pretende se concentrar. Como teremos a chance de ver, ocupa um lugar central na teoria da responsabilidade um certo "sentimento" de responsabilidade ${ }^{22}$, sentimento esse ligado a um estado de coisas objetivo e não meramente oriundo da homologia entre razão e vontade. Esse sentimento deriva das coisas, do ser temporal e o cuidado que este requer: "à luz dessa amplidão transcendente, torna-se evidente que a responsabilidade não é nada mais do que o complemento moral para a constituição ontológica do nosso ser temporal"23 (JONAS, 2006, p.187).

Diante de um estado de coisas como colocado na citação acima, como não tratar a responsabilidade como um epifenômeno? Qual a razão de ficarmos com o "complemente moral" se podemos ficar com o ser mesmo?

\footnotetext{
21 Op.Cit. 2008, p.86

22 Wendel Evangelista esmiúça que há um plano objetivo de fundamentação da metafísica de Jonas a partir de dois esforços centrais, um de caráter lógico metafísico e outro de caráter ontológico metafísico, sendo esses finalmente complementados por um plano subjetivo, o "intuicionismo". Cf: EVANGELISTA, Wendel. A Fundamentação Metafísica do Princípio Responsabilidade em Hans Jonas. 2008. 140 f. Dissertação (Mestrado em Filosofia) - Faculdade Jesuíta de Filosofia e Teologia, Belo Horizonte. $\quad$ Disponível em http://www.faculdadejesuita.edu.br/documentos/180915-K9SrJvvkVEd.pdf acessado em 05 julho 2016>. 23 Op.Cit. 2006, p.187
} 
Essas perguntas são, evidentemente, retóricas. É claro que Jonas se protegeu dessa falácia e também de outras possíveis. É que embora a teoria da responsabilidade seja bastante consistente, ela não está a salvo de problemas e dúvidas. Que tipo de relação pode haver entre ética e metafísica? Que tipos de relação existiram tradicionalmente? A proposta metafísica da ética da responsabilidade é uma resposta não apenas ao apelo do mundo contemporâneo, mas, também, às éticas contemporâneas? Jonas dialoga com essas éticas? Como é possível falar em dever depois de Nietzsche ter publicado "A Genealogia da Moral”? Como é possível uma ética metafisicamente fundada na conjuntura da filosofia contemporânea?

O ponto central da posição filosófica de Jonas é contundente: há um agir na natureza. Essa tese contraria todo tipo de posicionamento determinista e mecanicista do mundo natural. Ao se repensar este, é o lugar que o homem ocupa diante dele que também se modifica incisivamente: "isso implica que a eficiência dos fins não está exclusivamente vinculada à racionalidade, reflexão, livre escolha - portanto, ao homem"24.

Se verificarmos o ambiente das reflexões éticas do mundo contemporâneo, constataremos que boa parte das discussões derivam daquele esvaziamento dos sistemas metafísicos presentes na filosofia desde o século XIX. Não temos condições de fazer nenhum tipo de afirmação conclusiva, mas seria de se verificar que a emergência de uma pluralidade de discussões no âmbito da ética, e também da política, no mundo contemporâneo, parece ter uma consequência deste suposto fim da metafísica. E de fato parece haver uma urgência da ética, e os pensadores parecem não poder esperar mais por uma metafísica que sirva de fundamento para o mundo contemporâneo. Essa relação entre ética e metafísica interessa-nos aqui, pois acreditamos que Jonas encontre uma base de contribuição importante para essa discussão. A pergunta que se relaciona com esse problema é: há afinal um primado da ética, um primado metafisico ou não se

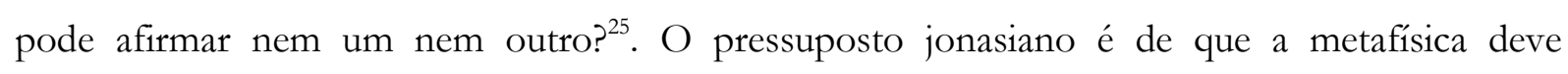
sustentar a ética. Em todo caso, é muito importante nos atentarmos como se dá essa relação, pois ela não parece acontecer de uma maneira usual, há algo inédito e interessante neste Princípio Responsabilidade.

O elementar do posicionamento jonasiano está no lugar que a finalidade ocupa no todo da vida. Mas não apenas se trata de atribuir fins meramente, pois o lugar da causa eficiente também é interpretado, e é isso o que permite a Jonas dar à liberdade um estatuto natural, pois ela está ligada ao fenômeno da vida e ao orgânico. De todo modo, ainda que esse seja um capítulo inteiramente à parte com relação à passagem da metafísica para a ética é preciso deixara claro o argumento de Jonas que parte da doutrina dos fins em direção à doutrina do valor. A

\footnotetext{
${ }^{24}$ Id.Ib., p.127-128

25 Op.Cit. 2008, p.45-46
} 
questão de Jonas é mostrar que fins imanentes reproduzem valores imanentes. Há um deslocamento de perspectivas que permite o autor de interpretar a partir do "ponto de vista da coisa" um fim imanente a si mesmo e a partir desse, um julgamento de valor de acordo com o próprio telos do objeto. Soa como Aristóteles, e de fato há autores que atribuem a Jonas um aristotelismo, algo de que não temos ainda condição de afirmar e que se revelará à medida que buscarmos as respostas de nossas principais questões. Mas, dizíamos, a finalidade imanente de determinada coisa é seu próprio valor: finalidade em si mesma e valor em si mesmo coincidem ${ }^{26}$. Esse parece ser o primeiro passo necessário em direção à ética da responsabilidade. Ou, como disse Hottois (1993) apud Evangelista (2008): a deontologia se revela no coração da ontologia. Jonas: "o homem não tem nenhuma outra vantagem em relação aos outros seres viventes, exceto a de que só ele também pode assumir a responsabilidade de garantir os fins próprios aos demais $\operatorname{seres}^{27,}$.

Ainda sem resultados prévios, porém à guisa de conclusão para este projeto, optamos por não denominarmos esta pesquisa de "A Inerência entre ética e metafísica", uma vez que o objeto de análise é menos a inerência entre as duas disciplinas filosóficas do que o espaço entre ambas. Pensamos também em outro título: "A confluência entre ética e metafísica", porém o termo não elucidava o conteúdo da preocupação, e parecia a mesma ideia do título anterior, pois aquilo que conflui de certo modo possui relação inerente. De maneira que optamos por "Entre a Ética e a Metafísica: a Fundamentação ontológica da Responsabilidade", pois sintetiza de modo geral a intenção de nossa pesquisa, que procura entender o lugar de cada uma dessas duas disciplinas filosóficas e sua relação no pensamento de Hans Jonas. Para a atual publicação, pensei em Os Caminhos Cruzados entre ética e metafísica, para manter essa ênfase que distingue o ético e o metafísico, dois caminhos em cruzamento.

\footnotetext{
${ }^{26}$ Id.Ib., p.61

27 Op.Cit.2006, p.175
} 


\section{REFERÊNCIAS}

JONAS, Hans. O Princípio Responsabilidade: ensaio de uma Ética para a civilização tecnológica. Tradução de Marijane Lisboa e Luiz Barros Montez. Rio de Janeiro: Contraponto: ed. PUC-RJ, 2006.

BRAZIL, Luciano Gomes. Consideraçoes Acerca do Princípio Responsabilidade de Hans Jonas in: VILAS BÔAS, João Paulo Simões; FAHRI NETO, Leon; PERIUS, Oneide (Org.). Filosofia em Debate: Questões de ética, educação e política. Florianópolis: Nefiponline, 2016. P.125$148<$ Disponível em http://www.nefipo.ufsc.br/files/2012/11/Quest \%C3\%B5esV3.pdf acessado em 30 agosto $2016>$

EVANGELISTA, Wendel. A Fundamentação Metafísica do Princípio Responsabilidade em Hans Jonas. 2008. 140 f. Dissertação (Mestrado em Filosofia) - Faculdade Jesuíta de Filosofia e Teologia, Belo Horizonte. <Disponível em http://www.faculdadejesuita.edu.br/documentos/180915K9SrJvvkVEd.pdf acessado em 05 julho 2016>.

GADAMER, Hans-Georg. A Ideia do Bem entre Platão e Aristóteles. Tradução de Tito Lívio Cruz Romão. São Paulo: editora Martins Fontes, 2009.

HEIDEGGER, Martin. A questão da técnica in Ensaios e Conferências. Tradução de Emmanuel Carneiro Leão. Petrópolis: Vozes, 2010. P.11-38 (Coleção Pensamento Humano).

KANT, Immanuel. Fundamentação da Metafísica dos Costumes. Tradução, introdução e notas de Guido Antônio de Almeida. São Paulo: Discurso Editorial: Barcarolla, 2009 (Coleções Philosophia)

SCHELER, Max. A Posição do Homem no Cosmos. Tradução e Apresentação de Marco Antônio Casanova. Rio de Janeiro: Forense Universitária, 2003.

SGANZERLA, Anor. Biologização do ser moral em Hans Jonas. Revista de Filosofia Aurora. Curitiba, V.25, n.36, p.155-178, jan./jun.2013 <Disponível em file://C:/Users/181/Downloads/rf-7769.pdf acessado em 06 julho 2016> 